\title{
PERBEDAAN POSISI PERSALINAN SETENGAH DUDUK DENGAN POSISI JONGKOK TERHADAP LAMANYA KALA II DI BPM ERNIWATY BABAT SUPAT
}

\author{
Untari Anggeni \\ Program Studi DIV Kebidanan STIKES Mitra Adiguna \\ Komplek Kenten Permai No. J 9-12 Bukit Sangkal Palembang \\ Email : untarianggeni@gmail.com
}

\begin{abstract}
Abstrak
Menurut World Health Organization (WHO), seorang tenaga kesehatan hendaknya membiarkan ibu bersalin dan melahirkan dalam posisi yang dipilihnya yang terdiri dari posisi berjongkok, posisi duduk dan semi duduk, posisi berlutut dan posisi berjongkok atau berdiri serta berbaring miring (lateral). Namun tidak dengan posisi telentang dan litotomi .Tujuan penelitian ini adalah untuk mengetahui perbedaan posisi persalinan setengah duduk dan posisi jongkok terhadap lamanya kala II di BPM Erniwaty Babat Supat Tahun 2018. Desain penelitian ini menggunakan analitik comparative. Populasi pada penelitian ini adalah seluruh ibu yang melahirkan anak pertama atau lebih dengan kala II persalinan normal di BPM Erniwaty Babat Supat tahun 2018 dan sampel penelitian ini terdiri dari 10 orang untuk kelompok eksperimen (posisi jongkok) dan 10 orang untuk kelompok kontrol (posisi setengah duduk). Hasil yang diperoleh distribusi frekuensi ibu bersalin pada posisi persalinan setengah duduk dengan waktu lama kala II yang normal sebanyak 10 orang (100\%) dan distribusi frekuensi ibu bersalin pada posisi persalinan jongkok dengan waktu lama kala II yang normal sebanyak 10 orang (100\%) serta ada perbedaan posisi persalinan setengah duduk dan posisi jongkok terhadap lamanya kala II ( $p$ value = $0,001>0,05)$.
\end{abstract}

\section{Kata Kunci : Lama Kala II, Posisi Persalinan Setengah Duduk Dengan Posisi Jongkok Referensi $\quad: 18(2005-2014)$}

Abstract

According to the World Health Organization (WHO), a health worker should allow the mother to give birth and give birth in the chosen position which consists of squatting position, sitting and semi sitting position, kneeling position and squatting or standing position and lying on his side (lateral). But not with the supine position and lithotomy. The purpose of this study was to determine the difference in half-sitting and squatting position to the duration of II in Erniwaty Babat Supat BPM in 2018 comparative analytic. The population in this study were all mothers who gave birth to their first or more children with a second stage of normal labor at Erniwaty Babat Supat BPM in 2018 and the sample consisted of 10 people for the experimental group (squatting position) and 10 people for the control group (half sitting position) The results obtained by the frequency distribution of maternity at half sitting position with a normal time period of 10 people (100\%) and the frequency distribution of maternity at the position of squatting labor with a normal duration II of 10 people (100\%) and there was a difference in the position of half-sitting labor and squatting position on the duration of second stage ( $p$ value $=0.001$ ) 0.05).

Keywords: Old Kala II, Position of Half Labor Sitting With Squatting Position Reference: 18 (2005-2014) 


\section{PENDAHULUAN}

Persalinan merupakan proses pergerakan keluarnya janin, plasenta dan membran dari dalam rahim melalui jalan lahir. Saat memberikan asuhan persalinan kala II ibu dianjurkan untuk mencoba posisi-posisi yang nyaman selama persalinan dan melahirkan bayi (Rohani, 2011). Persalinan adalah membuka dan menipisnya serviks dan janin turun kedalam rahim. Persalinan kelahiran normal adalah proses pengeluaran janin yang terjadi pada kehamilan cukup bulan ( 37-42 minggu ). Lahir spontan dengan presentasibelakng kepala, tanpa kompikasi baik ibu maupun janin ( Dwi Asri H, 2012 ). Posisi persalinan merupakan suatu peristiwa fisiologis tanpa disadari dan terus berlangsung/ progresif. Penolong persalinan dapat membantu agar ibu tetap tenang dan rileks, maka penolong persalinan tidak boleh mengatur posisi meneran. Penolong persalinan harus memfasilitasi ibu dalam memilih sendiri posisi meneran dan menjelaskan alternatifalternatif posisi meneran bila posisi yang dipilih ibu tidak efektif (Nuraisiah, 2012). Berdasarkan data dari WHO (World Health Organization), angka kematian ibu (AKI)diseluruh dunia mencapai angka 289.000 jiwa. Dimana terbagi atas bebarapa negara antara lain Amerika serikat mencapai 9300 jiwa, Afrika Utara 179.000jiwa dan Asia Tenggara 16.000 jiwa. Untuk AKI di Negara-negar asia tenggara dia antaranya mencapai 214 per 100.000 kelahiran hidup, fhilipina 170 per 100.000 kelahiran hidup, Vietnam 160 per 100.000 kelhiran hidup, Thailand 44 per 100.000 kelahiran hidup, brunei 60 per 100.00 kelahiran hidup, dan Malaysia 39 per 100.000 kelahiran hidup ( WHO 2015). Berdasarkan data dari kementerian kesehatan RI (Kemenkes RI), sepanjang tahun 2014 data menunjukan AKI di Indonesia mencapai 5.048 kasus, lanjut pada tahun 2015 berkurang menjadi 897 kasus dan data terakhir di tahun 2016 ada 4.834 kasus. Hal ini masih menjadi masalah besar karena tidak bisa mencapai Millenium Devolopment Goals (MDGs), yakni dengan angka 102 per 100ribu kelahiran. Sementara itu, angka target dari Sustainable Delevomrnt goals (SDGs) untuk angka kematian ibu sendiri adalah 70 per 100 ribu kelahiran (Kinanti, 2017). Untuk mencapai target Sustainable Development Goals (SDGs) dalam menurunkan angka kematian ibu harus ada penanganan dari berbagai sektor. Penanganan kematian harus di barengi dengan peningkatan derajat perempuan. Posisi perempuan yang lebih baikakan sangat membantu meningkatkan aksebilitas mereka terhadap pelayanan kesehatan dan fasilitasnya. Pemerintah juga harus memastikan semua tenaga kesehatan yang terlibat didalam penurunan AKI benar-benar bekerja, bekerja dan bekerja melakukan perubahan. Revoludi mental dillakukan dalam mempercepat penurunan AKI ini. Khususnya para pejabat di kementrian kesehatan yang umumnya tidak tahu persoalan di lapangan, harus melepaskan kacamata kuda kalau tidak ingin target AKI dalam SDGs pun berlau sia-sia sebagaimana MDGs (Fotarisman, 2017). Angka kematian ibu yang dilaporkan di Provinsi Sumatra Selatan berdasarkan data Profil Kesehatan tahun 2015 yaitu 165/100.000 
KH, Kabupaten Musi Banyuasin berjumlah 20 kasus. Namun bila dibandingkan dengan tahun sebelumnya lebih tinggin yaitu 155/100.000 KH. Jumlah kematian ibu di Provinsi Sumatra Selatan yang masih tinggi disebabkan oleh faktor perdarahan dalam persalinan berjumlah 55 kasus, hipertensi dalam kehamilan berjumlah 34 kasus, di sebabkan oleh penyakit infeksi berjumah 6 kasus, faktor lain berjumlah 55 kasus oleh gangguan system peredaran darah berjumlah $30 \mathrm{kasu}$, dan faktor ganguan metabolik berjumlah 4 kasus (Dinkes Provinsi Sumatra Selatan , 2016). Alasan posisi telentang dan litotomi tidak dianjurkan karena pada posisi telentang pembuluh aorta dan vena cava inferior akan tertekan oleh beban berat janin, uterus, air ketuban dan plasenta. Penekanan pembuluh darah besar ini akan mengganggu aliran darah ke janin sehingga janin akan kekurangan suplai oksigen yang berakibat terjadinya asfiksia intra uterus dan posisi litotomi tidak dianjurkan karena akan menyebabkan nyeri pada punggung dan kerusakan saraf kaki yang dirasakan setelah proses persalinan selesai (Sulistyawati, 2010). Posisi setengah duduk merupakan posisi yang paling umum diterapkan di rumah sakit/ rumah sakit bersalin di Indonesia. Pada posisi ini ibu duduk dengan punggung bersandar pada bantal, kaki ditekuk, dan paha dibuka ke arah samping. Posisi ini cukup dapat membuat ibu merasa nyaman (Rohani, 2011). Menurut Marmi (2012), posisi jongkok adalah posisi yang biasanya ibu berjongkok di atas bantalan empuk yang berguna menahan kepala dan tubuh bayi. Walaupun tidak lazim pada orang Indonesia bagian barat, cara bersalin jongkok sudah dikenal sebagai posisi bersalin yang alami bagi ibu di beberapa suku di Papua dan daerah lainnya. Oleh karena memanfaatkan gravitasi tubuh, ibu tidak usah terlalu kuat mengejan. Sementara bayi pun lebih cepat keluar lewat jalan lahir. Kelebihan posisi jongkok merupakan posisi melahirkan yang alami karena memanfaatkan gaya gravitasi bumi, sehingga ibu tidak usah terlalu kuat mengejan.

\section{METODE PENELITIAN}

Penelitian ini akan dilaksanakan di BPM Erniwaty babat supat dengan sasaran penelitian adalah20 orang ibu bersalin dengan persalinan anak pertama atau lebih secara normal. Penelitian ini direncanakan pada bulan Mei 2018. Desain penelitian ini menggunakan analitik comparative, yaitu penelitian dengan menggunakan metode studi perbandingan dilakukan dengan cara membandingkan persamaan dan perbedaan sebagai fenomena untuk mencari faktor apa atau situasi bagaimana yang menyebabkan timbulnya suatu peristiwa tertentu (Notoatmodjo,2010).

\section{Tempat dan waktu penelitian}

\section{Tempat penelitian}

Penelitian ini dilakukan di BPM Erniwaty Babat Supat Tahun 2018

\section{Waktu Penelitian}

Penelitian ini dilakukan sampai tanggal 30 Juni 2018.

\section{Data dan Tehnik atau Cara Pengumpulan Data}

\section{a. Data Primer}

Data primer yaitu data atau informasi yang langsung berasal dari yang mempunyai wewenang dan bertanggung jawab terhadap data tersebut (Notoatmodjo, 2005). Dalam penelitian ini 
data primer diperoleh dari hasil observasi langsung terhadap proses persalinan ibu bersalin dan dicatat dalam lembar hasil observasi.

\section{b. Data Sekunder}

Data sekunder yaitu data atau informasi yang bukan langsung dari orang yang ditanyai dan yang bukan atau dianggap tidak mempunyai wewenang dan tanggung jawab terhadap pemberian informasi atau data tersebut (Notoatmodjo, 2005). Dalam penelitian ini menggunakan data sekunder berupa jumlah ibu yang melakukan persalinan secara normal di BPM Erniwaty Babat Supat.

\section{Tehnik atau Cara Pengumpulan Data}

Cara pengumpulan data merupakan cara penelitian untuk mengumpulkan data yang akan dilakukan dalam penelitian. Sebelum mengumpulkan data, perlu dilihat alat ukur pengumpulan data tersebut antara lain dapat berupa kuesioner/ angket, observasi, wawancara atau gabungan ketiganya (Hidayat, 2007). Pada penelitian ini cara pengumpulan data menggunakan observasi.

\section{POPULASI DAN SAMPEL}

Populasi penelitian adalah keseluruhan subjek penelitian (Arikunto, 2006). Populasi pada penelitian ini adalah20 orang ibu bersalinyang melahirkan anak pertama atau lebih dengan kala II persalinan normal di BPM Erniwaty Babat Supat.

Sampel adalah sebagian yang diambil dari keseluruhan objek yang diteliti dan dianggap mewakili seluruh populasi (Notoatmodjo, 2005).

Sampel pada penelitian ini adalah ibu yang melahirkan anak pertama atau . lebih dengan kala II persalinan normal di BPM Erniwaty tahun 2018, terdiri dari 10 orang untuk kelompok Eksperimen (posisi jongkok) dan 10 orang untuk kelompok Kontrol (posisi setengah duduk), Sesuai dengan teori (Sugiyono, 2011).

\section{Tehnik Pengambilan Sampel}

Teknik pengumpulan sampel non random (nonprobability) Sampling adalah pengambil sampel yang tidak didasarkan atas kemungkinan yang dapat dihitungkan, tetapi semata-mata hanya berdasarkan kepada segi-segi kepraktisan belaka dengan metode purposive sampling adalah pengambilan sampel didasarkan pada suatu pertimbangan tertentu yang dibuat oleh peneliti sendiri berdasarkan ciri atau sifatsifat populasi yang sudah diketahui sebelumnya (Notoatmodjo, 2010).

Adapun ciri atau sifat populasi atau kriteria inklusi adalah:

a. Usia kehamilan aterm

b. Janin tunggal hidup

c. Persalinan normal

d. Bersedia menjadi partisipan dengan posisi persalinan setengah duduk dan posisi jongkok

e. Kooperatif.

\section{Tehnik Analisis}

Analisis data dalam penelitian ini melalui prosedur bertahap antara lain:

a. Analisis Univariat

Analisis univariat bertujuan untuk menjelaskan atau mendeskripsikan karakteristik setiap variabel penelitian. Pada umumnya dalam analisis ini hanya menghasilkan distribusi frekuensi dan persentasi dari tiap variabel (Notoatmodjo, 2010). Analisis data ini yang digunakan untuk melihat distribusi frekuensi dari tiap-tiap variabel yakni lamanya kala II pada kelompok posisi 
persalinan setengah duduk dengan persalinan kala II pada kelompok posisi persalinan jongkok.

b. Analisis Bivariat

Analisis ini untuk mencari pengaruh berdasarkan catatan hasil observasi pada kelompok posisi persalinan setengah duduk dan kelompok posisi persalinan jongkok dengan uji statistik yang sesuai dengan tujuan penelitian, yakni uji t-test independentsampel dengan taraf signifikan $\alpha=0,05$, dimana ketentuannya adalah jika nilai $\mathrm{p}$ value $>\alpha \quad(0,05)$ berarti tidak ada perbedaan dan jika $\mathrm{p}$ value $<\alpha(0,05)$ berarti ada perbedaan (Hastono, 2007). Pada penelitian ini menggunakan sampel ibu yang melahirkan anak pertama atau lebih dengan kala II persalinan normal di BPM Erniwaty babat supat tahun 2018, terdiri dari 10 orang untuk kelompok eksperimen (posisi jongkok) dan 10 orang untuk kelompok kontrol (posisi setengah duduk). Adapun gambaran umum

kelompok tersebut adalah dapat dilihat pada tabel 4.1.

Gambaran Umum Responden Ibu Bersalin DiBPM Erniwaty Babat Supat Tahun 2018

\begin{tabular}{ccc}
\hline No & Keterangan & Jumlah \\
\hline $\mathbf{1}$ & $\begin{array}{c}\text { Posisi persalinan } \\
\text { setengah duduk }\end{array}$ & $\mathbf{1 0}$ \\
$\mathbf{2}$ & $\begin{array}{c}\text { Posisi persalinan } \\
\text { jongkok }\end{array}$ & $\mathbf{1 0}$ \\
& Total & $\mathbf{2 0}$ \\
\hline \hline
\end{tabular}

Sumber: Hasil Penelitian tahun 2018

Analisis Univariat

Analisis data ini dilakukan untuk mengetahui distribusi frekuensi lamanya kala II pada posisi persalinan jongkok dan lamanya kala II pada posisi persalinan setengah duduk. Hasil penelitian terhadap masing-masing variabel akan diuraikan di bawah ini :

\section{Lamanya Kala II Posisi Persalinan Setengah Duduk}

Hasil penelitian setelah dilakukan pengujian langsung pada 10 orang ibu dengan posisi persalinan setengah duduk, maka dapat diketahui lamanya kala II sebagaimana terlihat pada tabel 4.1.3:

\section{Lamanya Kala II Pada Posisi}

Persalinan Setengah Duduk Di BPM

Erniwaty Babat Supat Tahun 2018

\begin{tabular}{llccc}
\hline No & $\begin{array}{l}\text { Lamanya } \\
\text { Pada } \\
\text { Persalinan Setengah } \\
\text { Duduk }\end{array}$ & $\begin{array}{r}\text { II } \\
\text { Posisi }\end{array}$ & N & \% \\
\hline $\mathbf{1}$ & Normal & 10 & $\mathbf{1 0 0}$ \\
$\mathbf{2}$ & Lambat & 0 & $\mathbf{0}$ \\
\hline \hline & Jumlah & $\mathbf{1 0}$ & $\mathbf{1 0 0}$ \\
\hline
\end{tabular}

Sumber: Hasil Penelitian tahun 2018

Dari tabel 4.1.3 diketahui dari 10 responden ibu bersalin pada posisi persalinan setengah duduk dengan waktu lama kala II yang normal sebanyak 10 orang (100\%).

\section{Lamanya Kala II Posisi Persalinan Jongkok}

Hasil penelitian setelah dilakukan pengujian langsung pada 10 orang ibu dengan posisi persalinan jongkok, maka dapat diketahui lamanya kala II sebagaimana terlihat pada tabel 4.1.4 :

\section{Lamanya Kala II Pada Posisi}

Persalinan Jongkok Di BPM Erniwaty

Babat Supat Tahun 2018

\begin{tabular}{llrll}
\hline No & $\begin{array}{l}\text { Lamanya } \\
\text { Pada }\end{array}$ & Kala II & N & $\%$ \\
& Posisi & & \\
& Persalinan Jongkok & & \\
\hline
\end{tabular}




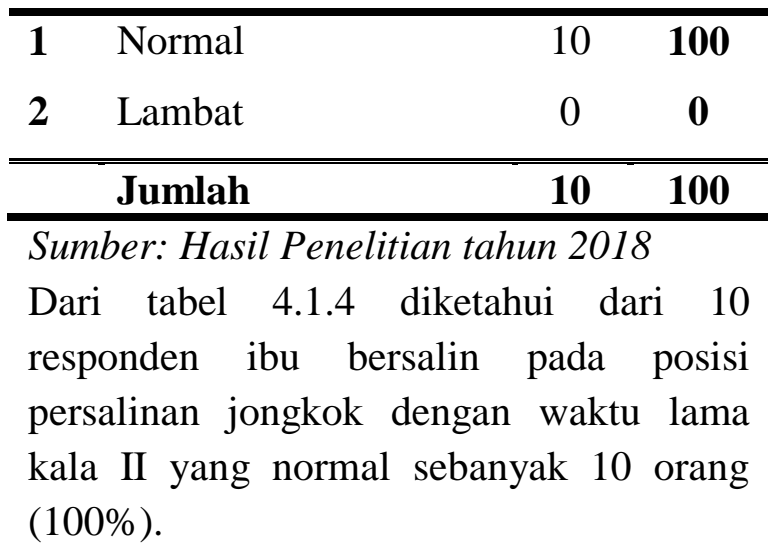

\section{Analisis Bivariat}

Analisis ini untuk mencari pengaruh berdasarkan catatan hasil observasi pada kelompok posisi persalinan setengah duduk dan kelompok posisi persalinan jongkok dengan uji statistik yang sesuai dengan tujuan penelitian, yakni uji t-test independentsampel dengan taraf signifikan $\alpha=0,05$, dimana ketentuannya adalah jika nilai $p$ value $\geq \alpha(0,05)$ berarti tidak ada perbedaan dan jika $p$ value $\leq \alpha(0,05)$ berarti ada perbedaan. Hasil penelitian dapat dilihat pada tabel 4.1.5

\section{Uji Normalitas Persalinan Posisi}

\begin{tabular}{|c|c|c|c|c|}
\hline \multicolumn{3}{|c|}{$\begin{array}{cc}\text { Setengah } & \text { Duduk } \\
\text { Jongkok Di } & \text { BPM } \\
\text { Supat Tahun } 2018 \\
\end{array}$} & $\begin{array}{l}\text { Dengan } \\
\text { Erniwaty }\end{array}$ & $\begin{array}{l}\text { Posisi } \\
\text { Babat }\end{array}$ \\
\hline No & Variabel & $\begin{array}{c}\text { Kolmog } \\
\text { orov- } \\
\text { smirno } \\
v\end{array}$ & $p$ & Status \\
\hline 1 & $\begin{array}{l}\text { Lamanya } \\
\text { Persalinan } \\
\text { kala II }\end{array}$ & 0,48 & 0,97 & Normal \\
\hline
\end{tabular}

Berdasarkan tabel 4.1.5 di atas, diketahui hasil uni normalitas untuk lamanya persalinan kala II mendapatkan nilai $p=0$, 97 berdasarkan ketentuan KolmogorovSmirnovbila $p \leq \propto 0,05$, maka distribusi data tersebut adalah normal. Selanjutnya analisis bivariat dilakukan untuk melihat perbedaan posisi persalinan setengah duduk dan posisi jongkok di BPM Erniwaty babat supat tahun 2018 dengan uji independent sampel $t$ Test, dengan tingkat kemaknaan alpha 0,05 dengan ketentuan jika $\leq 0,05$ bearti ada perbedaan dan jika $p$ value $\geq 0,05$ bearti tidak ada perbedaan.

\section{Rata-Rata Lamanya Kala II Ibu Bersalin Di BPM Erniwaty \\ Babat Supat Tahun 2018}

\begin{tabular}{cccccc}
\hline $\begin{array}{c}\text { Lamanya } \\
\text { Kala II }\end{array}$ & Mean & SD & SE & $\boldsymbol{P}$ & N \\
\hline $\begin{array}{c}\text { Posisi } \\
\text { setengah } \\
\text { duduk }\end{array}$ & 18,90 & 2,601 & 0,823 & 0,001 & 10 \\
$\begin{array}{c}\text { Posisi } \\
\text { jongkok }\end{array}$ & 13,90 & 2,846 & 0,900 & & 10 \\
& & & & &
\end{tabular}

\section{Sumber: Hasil Penelitian tahun 2018}

Dari tabel 4.1.5 dapat diketahui bahwa rata-rata waktu lamanya kala II ibu bersalin pada posisi setengah duduk adalah 18,90 , sedangkan untuk rata-rata waktu lamanya kala II ibu bersalin pada posisi jongkok adalah 13,90, perbedaan rata-rata antara setengah duduk dengan posisi jongkok adalah 5. Oleh karena rata-rata waktu lamanya kala II pada posisi setengah duduk lebih besar dari pada ratarata waktu lamanya kala II pada posisi jongkok sehingga dapat dinyatakan bahwa posisi persalinan jongkok efektif digunakan dalam asuhan persalinan normal kala II. Diperoleh nilai signifikansi sebesar 0,001 lebih besar dari taraf signifikansi 5\% atau $(p$ value $=0,001 \geq 0,05)$ maka dapat dinyatakan ada perbedaan yang signifikan antara rata-rata waktu lamanya kala II ibu 
bersalin pada posisi setengah duduk dengan rata-rata waktu lamanya kala II ibu bersalin pada posisi jongkok.

\section{Keterbatasan Penelitian}

Dalam pelaksanaan penelitian ini, tidak terlepas dari keterbatasan-keterbatasan yang terjadi serta kemungkinan yang tidak dapat dihindari walaupun telah diupayakan untuk mengatasinya. Peneliti menyadari kurangnya pengalaman dalam melakukan penelitian tentu hasilnya kurang sempurna dan banyak kekurangan.

Keterbatasan-keterbatasan

tersebut diantaranya:

a. Memerlukan waktu yang cukup lama untuk menunggu responden yang bersedia menggunakan posisi jongkok saat persalinan kala II, karena posisi ini masih sangat awam dan belum lazim digunakan.

b. Memerlukan kesabaran dalam memberikan penjelasan agar ibu bersalin bersedia menggunakan posisi jongkok dan setengah duduk, karena selama ini hanya tahu dan saat persalinan pertama menggunakan posisi litotomi yang saat ini tidak dianjurkan lagi untuk digunakan.

\section{PEMBAHASAN}

Berdasarkan hasil penelitian secara univariat terlihat distribusi frekuensi dari 10 responden ibu bersalin pada posisi persalinan setengah duduk dengan waktu lama kala II yang normal sebanyak 10 orang (100\%).Dan dari 10 responden ibu bersalin pada posisi persalinan jongkok dengan waktu lama kala II yang normal sebanyak 10 orang (100\%).

Pada tabel 4.1.6 menunjukkan bahwa ratarata waktu lamanya kala II ibu bersalin pada posisi setengah duduk adalah 18,90, sedangkan untuk rata-rata waktu lamanya kala II ibu bersalin pada posisi jongkok adalah 13,90 , perbedaan rata-rata antara setengah duduk dengan posisi jongkok adalah 5. Oleh karena rata-rata waktu lamanya kala II pada posisi setengah duduk lebih besar dari pada rata-rata waktu lamanya kala II pada posisi jongkok sehingga dapat dinyatakan bahwa posisi persalinan jongkok efektif digunakan dalam asuhan persalinan normal kala II.

Selanjutnya hasil penelitian secara bivariat uji $t$ nilai signifikansi sebesar 0,001 lebih besar dari taraf signifikansi $5 \%$ atau ( $p$ value $=0,001>0,05)$ maka dapat dinyatakan ada perbedaan yang signifikan antara rata-rata waktu lamanya kala II ibu bersalin pada posisi setengah duduk dengan rata-rata waktu lamanya kala II ibu bersalin pada posisi jongkok. Hasil penelitian ini sesuai dengan pernyataan Wiknjosastro (2008), jongkok atau berdiri membantu mempercepat kala II persalinan dan mengurangi rasa nyeri. Oleh karena memanfaatkan gravitasi tubuh, ibu tidak usah terlalu kuat mengejan, sementara bayi pun lebih cepat keluar lewat jalan lahir. Hasil penelitian ini juga sesuai dengan pernyataan Marmi (2012), walaupun tidak lazim pada orang Indonesia bagian barat, cara bersalin jongkok sudah dikenal sebagai posisi bersalin yang alami bagi ibu di beberapa suku di Papua dan daerah lainnya. Oleh karena memanfaatkan gravitasi tubuh, ibu tidak usah terlalu kuat mengejan. Sementara bayipun lebih cepat keluar lewat jalan lahir. Kelebihan posisi jongkok merupakan posisi melahirkan yang alami karena memanfaatkan gaya gravitasi bumi, sehingga ibu tidak usah terlalu kuat mengejan. Serta didukung oleh pernyataan Hasnerita (2012), posisi jongkok sudah dikenal sebagai posisi 
bersalin yang alami. Beberapa suku di Papua dan daerah lain memiliki kebiasaan melakukan persalinan dengan cara berjongkok seperti ini. Oleh karena memanfaatkan gravitasi tubuh, ibu tidak usah terlalu kuat mengejan. Sementara bayi pun lebih cepat keluar lewat jalan lahir. Tak heran karena berbagai keunggulan tersebut, beberapa RS/RSB di Jakarta menerapkan posisi persalinan ini untuk membantu pasiennya.

Hasil penelitian ini sejalan dengan hasil penelitian Julianti (2013) di BPM Kasih Ibu Kabupaten Gubuk Jawa Tengah tahun 2013, menunjukkan terdapat perbedaan lamanya persalinan kala II dengan posisi setengah duduk dan posisi jongkok di BPM Kasih Ibu Kabupaten Gubuk Jawa Tengah tahun 2013dengan hasil uji statistik uji $t$-test independent sampling nilai $p$ value $=0,001<\alpha(0,05)$, dengan kesimpulan sebagian besar lamanya kala II pada posisi jongkok lebih singkat dibandingkan posisi setengah duduk.

Hasil penelitian ini juga sejalan dengan hasil penelitian Pangestuti (2013) di Klinik Mitra Bunda Surakarta dari uji statisti uji $t$ independent sampling didapatkan nilai $\mathrm{p}$ value $0,000<\alpha \quad(0,05)$ berarti ada perbedaan lamanya kala II persalinan pada ibu bersalin menggunakan posisi jongkok dan posisi setengah duduk. Berdasarkan hasil penelitian dan teori serta pernyataan yang ada, peneliti berpendapat bahwa ada perbedaan posisi persalinan setengah duduk dan posisi jongkok terhadap lamanya kala II. Ini terjadi karena posisi jongkok secara tidak langsung akan memperluas rongga panggul dan penurunan bayi dibantu oleh gaya gravitasi bumi serta ibu bersalin tidak memerlukan tenaga yang banyak untuk mengeran namun waktu persalinan kala II akan berlangsung lebih singkat bila dibandingkan posisi setengah duduk titik berat berada pada tulang sakrum, sehingga tulang koksigis akan terdorong ke depan, dan akan menyebabkan rongga menjadi lebih sempit dan memerlukan tenaga meneran yang lebih kuat untuk mendorong bayi keluar dan melewati rongga panggul yang lebih sempit.

\section{SIMPULAN DAN SARAN}

Dari hasil penelitian yang dilakukan di BPM Erniwaty babat supat Tahun 2018 dari tanggal 17 mei sampai dengan 30 Juni 2018, mengenai "perbedaan posisi persalinan setengah duduk dan posisi jongkok terhadap lamanya kala II di BPM Erniwaty Babat supat Tahun 2018", maka dapat disimpulkan bahwa:

a. Distribusi frekuensi ibu bersalin pada posisi persalinan setengah duduk dengan waktu lama kala II yang normal sebanyak 10 orang (100\%).

b. Distribusi frekuensi ibu bersalin pada posisi persalinan jongkok dengan waktu lama kala II yang normal sebanyak 10 orang $(100 \%)$.

c. Ada perbedaan posisi persalinan setengah duduk dan posisi jongkok terhadap lamanya kala II ( $p$ value $=$ $0,001>0,05)$.

d. Ada perbedaan lamanya kala II pada posisi persalinan setengah duduk dan posisi jongkok dengan lamanya waktu 5 menit.

\section{SARAN}

Berdasarkan kesimpulan diatas maka penulis dapat mengemukakan saran sebagai berikut:

\section{Bagi Bidan}


Bidan memberikan Informasi tentang posisi-posisi persalinan yang sesuai dengan asuhan persalinan normal dan menyerahkan sepenuhnya kepada ibu bersalin untuk memilih posisi persalinan senyaman mungkin yang dirasakan ibu bersalin.

\section{Bagi STIKES Mitra Adiguna Palembang}

Diharapkan dapat menambah referensi kepustakaan tentang penelitian terdahulu, buku, jurnal kesehatan khususnya tentang persalinan dan posisi-posisi dalam persalinan untuk menambah atau menunjang penelitian selanjutnya.

\section{Bagi Peneliti Selanjutnya}

Penulis menyarankan hasil penelitian ini dapat menjadi bahan acuan bagi peneliti selanjutnya dan meneruskan penelitian mengenai lamanya persalinan kala II dengan posisi-posisi yang lainnya sesuai referensi yang ada di buku Asuhan Persalinan Normal terbitan Departemen Kesehatan Republik Indonesia, agar penelitian ini terus berkembang dan semakin akurat hasilnya.

\section{DAFTAR PUSTAKA}

Arikunto, Subarsimi. 2006. Prosedur Penelitian suatu pendekatan

Prakttik (Edisi Revisi VI). Jakarta : Rineka Cipta

Asrina, Siswoyo Putri Shinta, Sulistyorini Dewie, Syamrotul Muflihah Ima, Nirmala Sari Dian. (2010). Asuhan Kebidanan Masa Persalinan.Yogyakarta:Graha ilmu

Asri Dwi H, Clervo Cristine P (2012 ). Asuhan Persalinan Normal.
Yogyakarta : Nuha Medika

Dinas Kesehatan Provinsi Sumatera Selatan. (2016). Cakupan Pelayanan Persalinan dan Nifas.

Dinkes. (2016). Profil Dinkes Kota Palembang (online),(http://www.dinkeskota.co $\underline{\mathrm{m}}$, diakses pada tanggal 22 Oktober 2015)

Hasnerita. (2012). Posisi-Posisi Dalam Persalinan, at http://Posisi-DalamPersalinan. pdf.AdobeReader, diakses Maret 2014.

Hastono, Sutanto Priyo. (2007). Analisis Data Kesehatan. Jakarta: Fakultas Kesehatan Masyarakat Universitas Indonesia

Hidayat, A Aziz Alimul. (2007). Metode Penelitian Kebidanan dan Teknik Analisis Data. Jakarta : Salemba Medika.

Hidayat Asri, Sujiyatini ( 2010 ). Asuhan Kebidanan Persalinan. Yogyakarta : Nuha Medika

JNPK-KR,2008. Asuhan Persalinan Normal. Jakarta: Jaringan Nasional Pelatihan Klinik

Kemenkes RI, 2017. Survei Demografi dan Kesehatan Indonesia. Jakarta: Kemenkes RI

Marmi. (2012). Intranatal Care Asuhan Kebidanan Pada Persalinan. Yogyakarta: Pustaka Pelajar.

Nurasia, Ai, dkk. 2012. Asuhan Persalinan Normal Bagi Bidan. Bandung: Retika Aditama

Notoatmodjo, S. (2005). Metodologi Penelitian Kesehatan. Jakarta : Rineka Cipta 
Notoatmodjo (2010). Metodologi

Penelitian Kesehatan. Jakarta:

Rineka Cipta.

Praworhardjo, Sarwono. (2008). Ilmu

Kebidanan. Jakarta: BP-SP.

Rohani, dkk. (2011). Asuhan Kebidanan

Pada Masa Persalinan. Jakarta :

Salemba Medika.

Saifuddin, Abdul Bari. (2009). Buku Acuan Nasional Pelayanan Kesehatan Maternal dan Neonatal. Jakarta : Yayasan Pustaka Sarwono Prawirohadjo.

Sugiyono. (2011). Metode Penelitian

Kuantitatif Kualitatif Dan $R \& D$.

Bandung : Alfabeta

Sulistyawati, Ari. (2010). Asuhan

Kebidanan Pada Ibu Bersalin.

Jakarta: Salemba Medika

Wiknjosastro, Gulardi H. (2008). Asuhan

Persalinan Normal Asuhan

Esensial. Jakarta : JNPK-KR

Depkes RI 